\title{
PReS-FINAL-2064: Effect of Goloimumab a new anti-TNF, in patients with the diagnosis of juvenile idiopathic arthritis
}

\author{
A Kienast, I Foeldvari \\ From 20th Pediatric Rheumatology European Society (PReS) Congress \\ Ljubljana, Slovenia. 25-29 September 2013
}

\section{Introduction}

Golimumab is a fully human monoclonal antibody targeting tumor necrosis factor-alpha (TNF- $\alpha$ ), which plays an important role in the pathogenesis of juvenile idiopathic arthritis. Golimumab was approved for the treatment of rheumatoid arthritis, psoriatic arthritis and ankylosing spondylitis.

\section{Objectives}

To assess the effectivity and safety of Gololimumab in juvenile idiopathic arthritis.

\section{Methods}

We analysed retrospectively the data of all our patients who have been treated with Golimumab (Simponi ${ }^{\circledR}$ ) every 28 days sub cutaneously.

\section{Results}

18 patients with the diagnosis of juvenile idiopathic arthritis (15 with juvenile enthesitis associated arthritis, 2 with juvenile psoriatic arthritis and 1 with juvenile idiopathic polyarticular arthritis), for a mean time of 13.7 months per patient (4-26 months). 16 patients have been treated with other biologic agents before. In 13 patients Golimumab was started because of disease progression, in 3 because of intolerance to other biologic agents and in 2 because they described severe phobia of injections. Mean number of painful, swollen and limited joints were before and at the end of the treatment period after 13.7 months (4.5/2.39; $1.78 / 0.94 ; 2.72 / 2.83)$. The mean value at baseline after the mean follow up were of the physician global assessment score $(2.03 / 0.84)$, mean erythrocyte sedimentation

Hamburger Zentrum für Kinder-und Jugendrheumatologie, Hamburg, Germany 